\title{
MECHANISM OF THERMAL INTERACTION OF In WITH GaAs*
}

\author{
A. Barcz, J. Adamczewska \\ Institute of Electronic Technology, Al. Lotników 46, 02-668 Warszawa, Poland
}

\section{J.M. BARANOWSKI}

Institute of Experimental Physics, University of Warsaw

Hoża 69, 00-681 Warszawa, Poland

AND S. KWIATKOWSKI

Institute for Nuclear Problems, Hoża 69, 00-681 Warszawa, Ṗoland

General behavior of $\mathrm{In} / \mathrm{GaAs}$ couple heat-treated at $570^{\circ} \mathrm{C}$ for 2 hours was studied with secondary-ion-mass spectrometry, scanning electron microscopy, Rutherford backscattering spectroscopy and Nomarski microscopy. It is shown that, besides the well-known InGaAs crystallites which epitaxially grow upon dissolution of the substrate, In interacts with the substrate dislocations to form $\operatorname{In}(\mathrm{Ga})$ As dendrites. The driving force for this process is presumably excess arsenic reported to be present in the vicinity of the individual dislocations.

PACS numbers: $73.40 . \mathrm{Ns}$

Indium layers on GaAs are frequently used to assure adequate electrical, thermal or mechanical contact to the semiconductor substrate [1-3]. Recently, In-GaAs system was also found to exhibit a superconductive frequency-modulated microwave absorption signal at temperatures of 6-8 K [4].

The aim of this work is to establish a final configuration to which the In-GaAs couple would evolve under prolonged heating.

The samples were prepared by deposition of $15 \mu \mathrm{m}$ In onto a polished (100)GaAs surface. The substrates were either Czochralski-grown with etch pit density (epd) of $10^{5} / \mathrm{cm}^{2}(\mathrm{CZ})$, Bridgman-grown with epd $=200 / \mathrm{cm}^{2}$ (B) or as the latter but implanted with Ar ions to a dose of $5 \times 10^{15} / \mathrm{cm}^{2}$ at an energy of $300 \mathrm{keV}$ (I). Annealing was performed for up to 2 hours at a temperature of $570^{\circ} \mathrm{C}$, i.e. below the temperature of spontaneous decomposition of GaAs. After chemically removing the remaining $\operatorname{In}(\mathrm{Ga}, \mathrm{As})$ solution, the samples were analysed using secondary-ion-mass spectrometry (SIMS), Rutherford backscattering

*Two of the authors (JMB and AB) wish to thank the Committee for Scientific Research for financial support under contracts 223689203 and 801219101 , respectively. 
spectroscopy (RBS), X-ray diffraction, scanning electron spectroscopy (SEM) and optical microscopy with Nomarski contrast.

In all cases, SEM investigation reveals on the processed surface two distinct areas: deeply decomposed regions with randomly distributed crystallites and apparently intact areas. The crystallites have been identified by X-ray diffraction as $\mathrm{In}_{x} \mathrm{Ga}_{1-x}$ As grains of a range of compositions $x=0.05-0.2$ (Fig. 1). SIMS depth

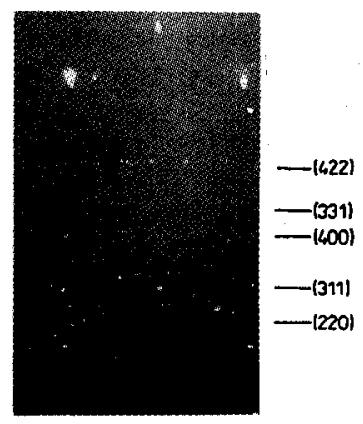

Fig. 1. X-ray diffraction pattern obtained from the reacted region of $\mathrm{In} / \mathrm{GaAs}$ annealed at $570^{\circ} \mathrm{C}$ for $2 \mathrm{~h}$ with reflections corresponding to individual InGaAs clusters.

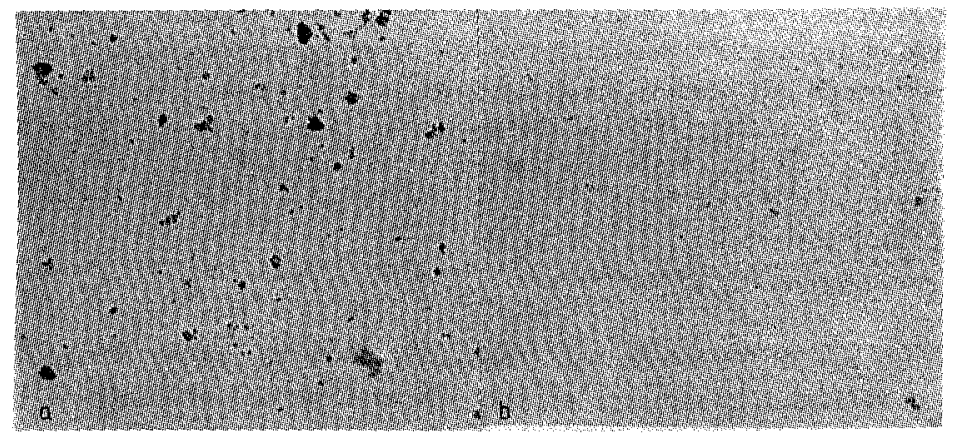

Fig. 2. Nomarski micrographs showing the In-rich inclusions outside the reacted regions in: (a) CZ-grown GaAs with epd $=10^{5} / \mathrm{cm}^{2}$, (b) Bridgman-grown GaAs, epd $=200$. The samples were polished to remove about $300 \mathrm{~nm}$ of the substrate. The area shown is $0.5 \times 0.5 \mathrm{~mm}$.

profiling taken on the smooth parts of the surfaces, outside the reacted regions, showed that the extent of In penetration critically depends on the crystalline quality of the substrate and is much larger in GaAs (CZ) than in (B). For the substrate (I) the obtained In profile closely matches that of the distribution of defects generated by the implanted ions. Nomarski micrographs of the regions which appeared featureless by SEM, give clear evidence that In migrates through an array of spikes or dendrites whose density scales with the density of crystal imperfections characterized by the epd number (Fig. 2). SIMS analysis performed on the sample B at 
a spot free of the In-rich indentations yielded no trace of indium.

It is proposed that in the course of agglomeration, indium is being preferentially located at the dislocations extending to the semiconductor surface. It is likely that the driving force for indium to protrude along the dislocations is reaction with excess arsenic, which is reported to be present in their vicinity [5]. Such interpretation seems consistent with the observed reduction in the epd number [6] or immobilization of $\alpha$-dislocations [7] in GaAs doped with indium to about $10^{20} / \mathrm{cm}^{2}$ relative to the In-free crystal. The tendency for In to interact with dislocations in GaAs results most probably from the high negative value of the enthalpy change associated with reaction In + As $\rightarrow$ InAs.

No sign of classical isotropic diffusion of In into GaAs at the considered temperature was found.

\section{References}

[1] A.A. Lakhani, J. Appl. Phys. 56, 1888 (1984).

[2] J. Ding, J. Washburn, T. Sands, V.G. Keramidas, Appl. Phys. Lett. 49, 818 (1986).

[3] M. Murakami, H.J. Kim, W.H. Price, M. Norcott, Y.C. Shih, Mater. Res. Soc. Symp. Proc. 148, 151 (1989).

[4] J.M. Baranowski, Z. Liliental-Weber, W.-F. Yau, E.R. Weber, Phys. Rev. Lett. (Reply) 68, 551 (1992).

[5] P. Kidd, D.J. Stirland, G.R. Booker, Mater. Lett. 9, 521 (1990).

[6] G. Jacob, M. Dusseaux, J.P. Farges, M.M.B. van den Boom, P.J. Roksnoer, J. Cryst. Growth 61, 417 (1983).

[7] I. Yonenaga, K. Sumino, K. Yamada, Appl. Phys. Lett. 48, 327 (1986). 